\title{
“T” Tooth: A Sporadic Labial Talons
}

\author{
Karthikeya Patil", Mahima V G, S. Shreenivas \\ Department of Oral Medicine and Radiology, J S S Dental college, Mysore, Karnataka, India \\ *Corresponding author: patilkarthik@gmail.com
}

Received December 05, 2014; Revised December 12, 2014; Accepted January 05, 2015

\begin{abstract}
A talon cusp is a rare form of developmental anomaly characterized by a well-delineated additional cusp like projection located on the surface of an anterior tooth and extends at least half the distance from the cementoenamel junction to the incisal edge. It usually occurs on palatal and lingual surface of the anterior teeth. On rare occasions the cusp may project from the facial surface or from both surfaces of a single tooth. When it occurs on facial surface of anterior teeth, the prime consideration is aesthetics, plaque retention and function. Regular followup is required to avoid any periapical changes. Here we report a rare case of Labial Talon cusp in Maxillary Central Incisor of a 45 year old male patient found incidentally on routine clinical examination.
\end{abstract}

Keywords: labial talon, tubercle, central incisor, cusp, cingulum

Cite This Article: Karthikeya Patil, Mahima V G, and S. Shreenivas, ““T” Tooth: A Sporadic Labial Talons.” International Journal of Dental Sciences and Research, vol. 3, no. 1 (2015): 13-16. doi: 10.12691/ijdsr-3-1-4.

\section{Introduction}

Talon cusp is an unusual cuspal projection from an anterior tooth with normal enamel and dentin containing varying degrees of pulp tissue. [1,2] It is otherwise referred to as dens evaginatus, tuberculated premolar, interstitial cusp, occlusal anomalous tubercle, odontoma of the axial core type, occlusal enamel pearl, evaginated odontoma, supernumerary cusp and occlusal enamel pearl, of which dens evaginatus is used for both anterior and posterior teeth $[3,4]$.

Talon cusp was first recorded by Mitchell in 1892. She described this accessory cusp on the lingual surface of a maxillary central incisor as "a process of a horn-like shape curving from the base downward to the cutting edge" in a female patient. This condition was termed by Mellor and Ripaas “Talon cusp” because of its resemblance to an Eagle's talon $[2,4]$.

The exact etiology of this condition is unknown. Prevalence of talon cusp varies considerably among ethnic groups ranging from $0.06 \%$ to $7.7 \%$. The reported prevalence is $0.6 \%$ in Mexicans, $7.7 \%$ in a northern Indian, $2.5 \%$ in a Hungarian, $5.2 \%$ in Malaysian, and $2.4 \%$ in Jordanian population. [5] It has high predilection for the maxillary teeth over the mandibular teeth and its occurrence is more common in males than females [1,2].

Three fourths of all reported talon cusps are located in the permanent dentition. The cusp predominantly occurs on permanent maxillary lateral (55\%) orcentral (33\%) incisors but are less frequently on mandibular incisors (6\%) and maxillary canines (4\%). Their occurrence in the deciduous dentitionis very rare, with vast majority of cases noted on deciduous maxillary central incisors [1].

Talon cusp usually occurs on the lingual surfaces of teeth. On rare occasions the cusp may project from the facial surface or from both surfaces of a single tooth. [1] The frequency of occurrence of labial talons cuspvaries widely in different ethnic groups. According to one study, low prevalence was observed for American children (0.25\%), while in Chinese and Arab populations it was considerably higher(6.9 \%). [6] A deep developmental groove may be present where the cusp fuses with the underlying surface of the affected tooth [1].

Here, were port a rare case of Labial Talon cusp in Maxillary Central Incisor of a 45 year old male patient found incidentally on routine clinical examination.

\section{Case Report}

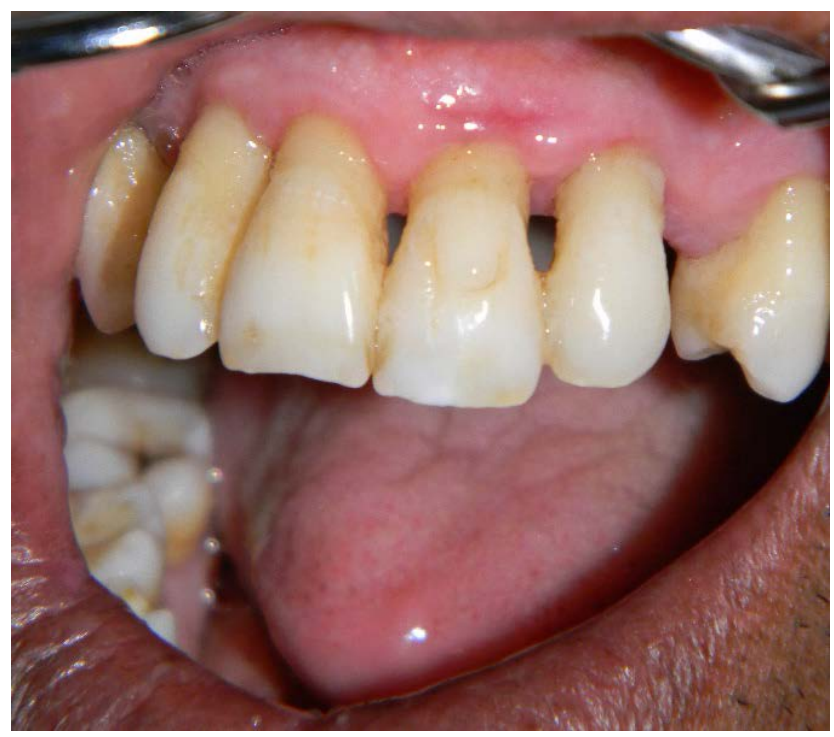

Figure 1. Talons cusp on the Labial Surface of 21

A 45 year old male patient reported to us with a chief complaint of stains and deposits in his teeth. Intraoral 
examination revealed well- defined accessory cusp on the labial surface of permanent maxillary left Central Incisor (FDI Tooth no. 21). Patient gave a history of its presence since the time the tooth erupted. The accessory cusp was raised, tubular in shape and extended from the gingival margin to the middle $3^{\text {rd }}$ of the tooth.

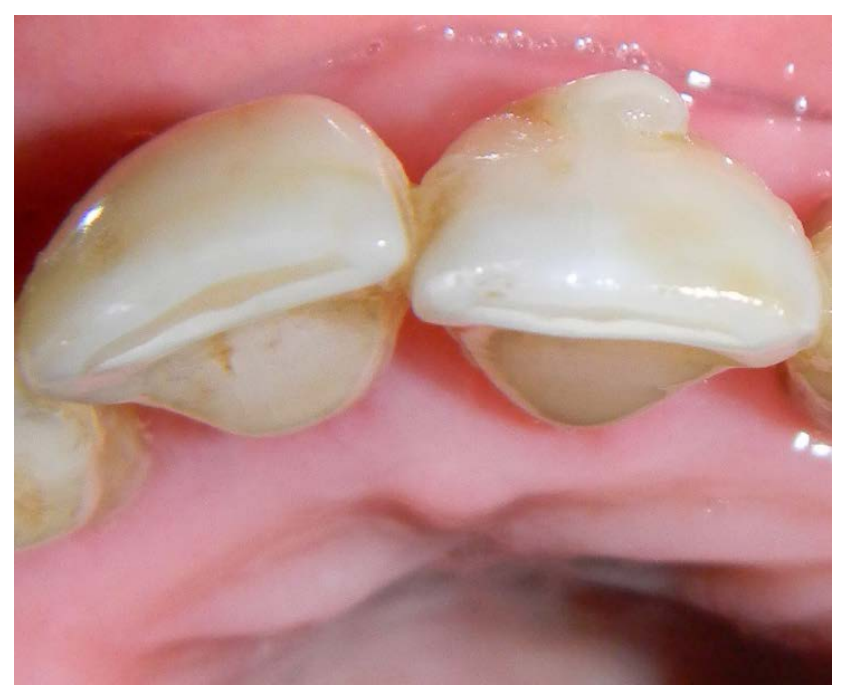

Figure 2. "T" Shaped configuration from the incisal surface of 21

It was located in the middle of crown and completely attached to it. The morphology of the permanent maxillary left centralincisor was unique.

The tooth was inverted "T" shaped when viewed from the incisal aspect. No carious lesions and spontaneous or percussion pain were associated with the concerned tooth.

An intraoral periapical radiograph of the Tooth no. 21, as well as Maxillary Anterior Occlusal Radiograph revealed a well-defined " $U$ " shaped or a tooth shaped projection from the middle $3^{\text {rd }}$ of crown to the CEJ with the pointed end of the " $U$ " toward the incisal edge giving it a tooth within a tooth appearance.

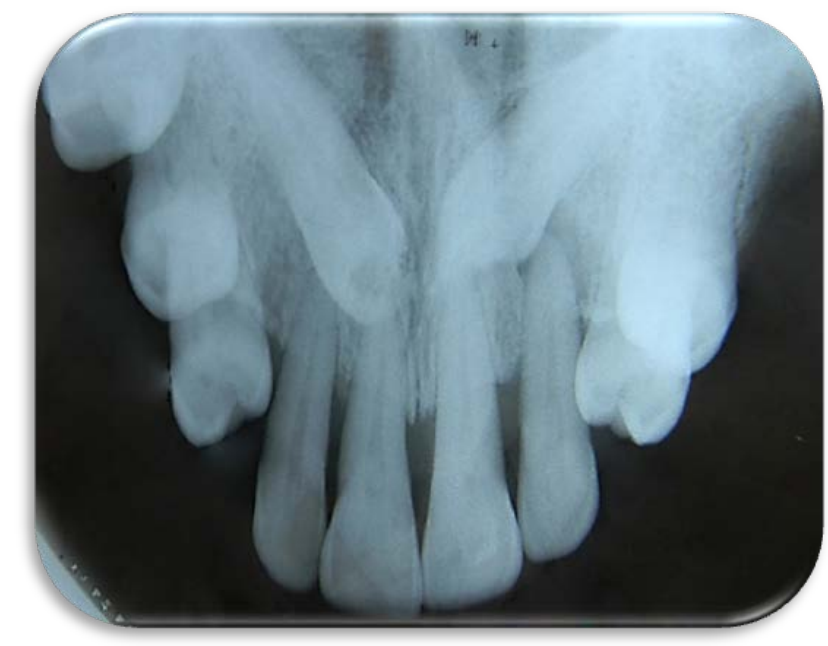

Figure 3. Maxillary anterior occlusal view showing "U" shaped or a tooth shaped radiopacity in the middle $3^{\text {rd }}$ of crown of 21

The radiographs were digitized and inverted. The digitized inverted radiographs showed clear delineation of the accessory tubercle form the rest of the tooth. Other radiological findingsincluded advanced bone loss and impacted maxillary left and right maxillary canines.

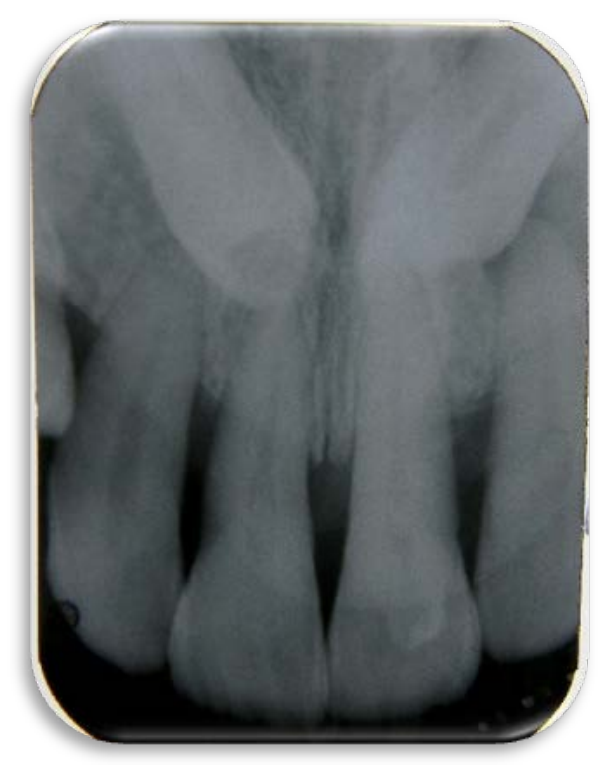

Figure 4. IOPAR showing "U" shaped or a tooth shaped radiopacity in the middle $3^{\text {rd }}$ of crown of 21

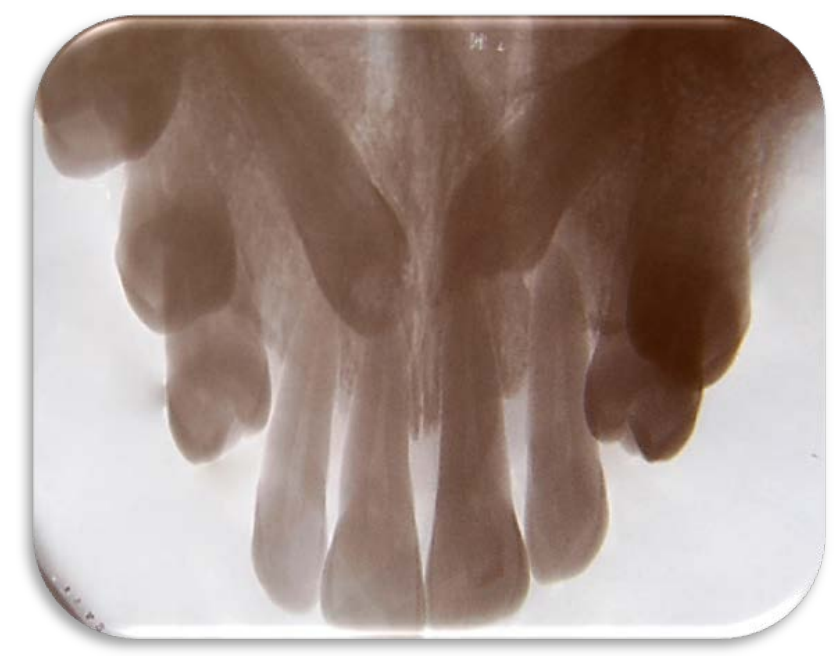

Figure 3. "Inverted" Maxillary anterior occlusalimage showing "U" shaped or a tooth shaped radiopacity in the middle $3^{\text {rd }}$ of crown of 21

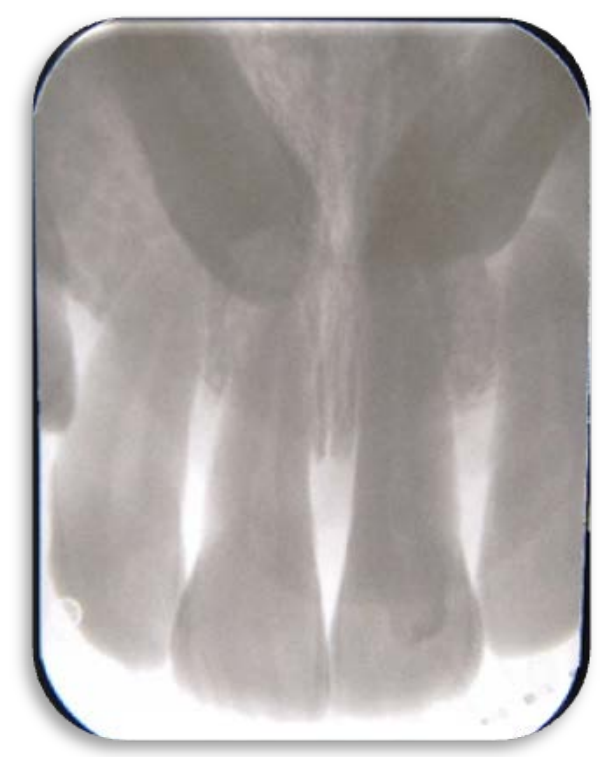

Figure 4. "Inverted" IOPAR imageshowing "U" shaped or a tooth shaped radiopacity in the middle $3^{\text {rd }}$ of crown of 21 
Since the chief complaint of the patient was stains and deposits in his teeth, oral prophylaxis was done in the initial visit. Cusp recontouring $\backslash$ reduction was planned but the patient denied treatment. Hence patient was counseled and managed with prophylactic fluoride application. The patient is under regular follow up and has not reported with any complications.

\section{Discussion}

Talon cusp or dens evaginatus is a rare anomaly with multifactorial etiology including both genetic and environmental factors. The exact etiology is still unknown but various theories have been proposed. Hattab et al suggested that the anomaly might occur because of outfolding of the enamel organ. Hyperactivity of the dental lamina was also considered as a potential etiological factor. [6] Sicher and Bhasker suggested that any disturbance during the morphodifferentiation stage (eg, altered endocrine function) of tooth development can affect the size and shape of the tooth [4].

There is also a suggestion of a strong genetic influence in its formation as evidenced by its occurrence in close family members [7].

Hattab et al [6] classified anomalous cusp based on the extent from the cementoenamel junction towards the incisal edge into 3 types:

Type 1- It occurs as well-delineated projections from the palatal surface of primary or permanent anterior teeth and extending at least half the distance from the CEJ to the incisal edge.

Type 2- If the projection is small, extending less than half the distance from theCEJ to the incisal edge, they are referred to as type 2 semi-talon cusps.

Type 3 - also known as trace talon cusps are prominent cingula, which vary in shape (conical, bifid, or tubercle).

But this classification was proposed for lingual talon cusps and was not applicable for labial talons cusp.

Based on the Size and Extension, Chin-Ying [8] described 3 different types of talon cusps occurring on the anterior tooth's facial or palatal/lingual surfaces:

Major talons: well-delineated cusps that project and extends at least half the distance from the cementoenamel junction to the incisal edge;

Minor talons: it extend more than one fourth and less than half the distance from the cementoenamel junction to the incisaledge;

Trace talons: It occurs as an enlarged prominent cingula and their variations occupying less than one fourth the distance from the cementoenamel junction to the incisal edge.

Based on the above classification, our case falls into the category of Major talons.

Mayes [9] classified facial talon cusps into three stages based on the extent of the Cusp:

Stage 1: The slightest form, consisting of slightly raised triangle on the labial surface of an incisor extending the length of the crown, but not reaching the CEJ or the incisal edge;

Stage 2: The moderate form, comprising of a raised triangle on the labial surface of an incisor that extends the length of the crown, does not reach the CEJ, but does reach the incisal edge, and can be observed clearly and palpated easily at this stage.

Stage 3: The most extreme form, consisting of a freeform cusp, extending from the CEJ to the incisal edge on the labial surface of an incisor. Talon cusp is an uncommon odontogenic anomaly.

Based on the above classification, our case belonged to Stage 1.

According to Gorlin and Goodman, a talon cusp is defined as a high accessory cusp reaching the incisal edge to produce a T-form or a Y-shaped tooth crown. Earlier definition of talon cusp included only those accessory cusp projecting incisally from the cingulum of an incisor. The present definition includes accessory cusp on the labial aspect or lingual of incisors or canines. [10] Our case presented with a “T- Form” configuration.

The talon cusp have been found to be associated with syndromes such as Rubinstein-Taybi syndrome, Sturge-Weber syndrome (also called as encephalotrigeminalangiomatosis), incontinentiapigmentiachromians, orofacialdigital syndrome II (Mohr syndrome) and Ellis-van Creveld syndrome. [4] Our patient did not show signs suggestive of any such syndromes.

The main objective of the treatment is to provide better esthetics, function (elimination of occlusal/ Incisal interferences) and prevent the occurrence of dental caries, periodontal problems in the involved tooth. The treatment of talon cusp may range fromconservative management to radical treatment, depending on the shape, sizeand location of the affectedtooth. Periodic and gradual reduction of the cusp/ recontouring followed byapplication of a desensitizing agent/ Fluoride agents, reduction of cusp with or without endodontic therapy, application of pit and fissure sealants on the grooves and esthetic restorations are the various treatment options available [11].

No treatment was carried out in this case for the tooth no. 21 except oral prophylaxisand fluoride application as the patient succumbed treatment.

To conclude, as dental experts one should have a thorough knowledge of anatomy of teeth and their variations prove indispensable infacilitating prompt treatment, restoringestheticsand preventing further complications associated with it.

\section{References}

[1] Neville BW, Damm DD, Allen CM, Bouquot JE. Oral and Maxillofacial Pathology. $3^{\text {rd }}$ ed. Philadelphia: WB Saunders Co; 2010: 87-89.

[2] Shafer WG, Hine MK, Levy S. Shafer's Textbook of Oral Pathology. $6^{\text {th }}$ ed. Philadelphia: WB Saunders Co; 2009: 41-43.

[3] Tsai AI, Chang PC. Management of talon cusp affectingthe primary central incisor: A case report. ChangGung Med J 2003; 26 : 678-683.

[4] Jeevarathan et al. Labial and lingual talon cuspsof a Primary Lateral Incisor: A Case Report. Pediatr Dent 2005; 27: 303-306.

[5] Safadi RA, Hamasha AH. Prevalence of talon cusps in Jordanianpermanent teeth: A radiographic study. BMC Oral Health 2010; 10: 6.

[6] Hattab FN, Yassin OM, Al-Nimri KS. Talon cusp in the permanentdentition associated with other dental anomalies: Review of literatureand reports of seven cases. J Dent Child 1996; 63: 368-76. 
[7] Thakur S, Gupta R, Thakur NS, Gupta M. Facialtalon cusp on permanent maxillary canine: A rare dental anomaly. Eur $\mathrm{J}$ GenDent 2013; 2: 324-7.

[8] Chin-Ying SH, Girija V, Fei YJ. Bilateral talon cuspin primary teeth: Clinical significance and treatment.J Dent Child 2001; 68: 239-243.
[9] Mayes AT. Labial talon cusp: A case study of pre-EuropeancontactAmerican Indians. J Am Dent Assoc 2007; 138:515-8.

[10] D. Glavina and T. Skrinjaric: Labial Talon Cusp on Incisors, Coll. Antropol. 29 (2005) 1: 227-231.

[11] Andresa Borges Soares, JuJianaJuJianelli de Araujoe MariaGalvao de Sousa, Maria Cecilia Veronezi. Bilateral talon cusp:Case report. Quintessence Int 2001; 32: 283-286. 